\title{
Sonhando Moçambique
}

\author{
Andréa Vilela Gouvêa Quadra \\ Raquel Costa Chaves \\ Universidade Federal de Minas Gerais
}

\section{Lendo as estórias de Moçambique}

Talvez, quem sabe, cumprisse o que sempre fora: sonhador de lembranças, inventor de verdades. Um sonâmbulo passeando entre o fogo. Um sonâmbulo como a terra em que nascera.

Kindzu

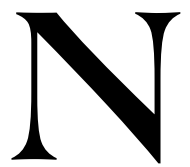

ão há como dissociar o momento histórico vivido pela população de Moçambique dos rumos que vem tomando a produção cultural daquele país, em especial a produção literária. Como nação que lentamente se liberta do jugo da colonização, mas que já foi (e ainda é) marcada pela cultura do outro, Moçambique tem, na literatura, autores que conseguiram evidenciar a existência dessa tensão entre a tradição e a "cultura nova" que se infiltrou no território africano principalmente a partir do processo de colonização.

Mia Couto, em seu romance Terra sonâmbula, aponta de forma sensível e desvestida de preconceitos a existência dessa teia de influências que atua na construção da identidade do povo moçambicano. Nessa obra, tanto quando a narrativa se aproxima de uma visão da História, quanto quando se diversifica nas estórias várias - sinais de particularização e, ao mesmo tempo, identificadoras de uma cultura comum - essa tensão é nitidamente percebida. Mas é também percebida a tentativa de se construir um modelo de nação que seja uma síntese harmônica desses dois estados. O caráter mestiço da nova Moçambique seria esse terceiro "estado de alma" do povo que tenderia a harmonizar essa tensão.

O próprio Mia Couto, em uma conferência proferida na AMECON - Associação Moçambicana de Economistas, revela que o continente africano 
é feito de profunda diversidade e de complexas mestiçagens. Longas e irreversíveis misturas de culturas moldaram um mosaico de diferenças que são um dos mais valiosos patrimônios do nosso continente. Quando mencionamos essas mestiçagens falamos com algum receio como se o produto híbrido fosse qualquer coisa menos pura. Mas não existe pureza quando se fala da espécie humana. Os senhores dizem que não há economia actual que não se alicerce em trocas. Pois não há cultura humana que não se fundamente em profundas trocas de alma.

Representar ou questionar a História, numa perspectiva não-positivista e tendo a ficção como forma de tornar observáveis vários pontos de vista sobre os acontecimentos, parece ter sido o plano de Mia Couto em Terra sonâmbula. O romance retrata essas constantes "trocas de alma" que fazem parte da História moçambicana, focando o período da guerra civil pós-independência política em relação a Portugal.

Neste trabalho, pretendemos analisar o romance observando dois pares de aspectos que, se em princípio parecem se constituir como dicotômicos, acabam por revelar, na obra, a defesa dessa mestiçagem como condição harmonizadora da tensão entre tradição e "cultura nova": oral/escrita; sonho/lógica e racionalidade. Para amparar nossas discussões, o complexo processo narrativo da obra é que se constituirá como corpus da nossa investigação.

Narrativas dentro de narrativas: esse é o modo de construção desse romance que, ao apresentar essas variadas vozes narradoras, valoriza tanto a cultura oral - marca da tradição moçambicana - quanto a cultura escrita, que poderia aparecer, nesse cenário, como a expressão da supremacia do colonizador sobre os colonizados, mas que, por meio da arquitetura da obra, aparece desfazendo a polaridade entre esses usos da linguagem.

Os dois extremos, que, por vezes, insistem violentamente em se opor em Terra sonâmbula, aparecem também quando o autor moçambicano lança mão de toda uma atmosfera onírica, como se nesse lugar estivesse a representação da tradição, ao mesmo tempo em que a guerra acorda o povo para a racionalidade. Mas em seu plano de defesa da mestiçagem, Mia Couto encontra um estado sonhambulante: estado de quem sonha, mas age como se estivesse acordado. Aí estaria a síntese. O povo moçambicano não precisa perder a tradição para incorporar valores novos. Como o próprio autor afirma, no texto da conferência já citada neste trabalho,

essas coisas [produtos que são representações do que é tipicamente nacional em Moçambique e que, na verdade, têm origem estrangeira] 
acabam sendo nossas porque, para além da sua origem, lhes demos a volta e as refabricamos à nossa maneira. A capulana pode ter origem exterior mas é moçambicana pelo modo como a amarramos. E pelo modo como esse pano passou a falar conosco. O coco é indonésio, a mandioca é mais latino-americana que a Jennifer Lopez mas o prato que preparamos é nosso porque o fomos caldeando à nossa maneira.

Assim, o grande SONHO, na obra, passa a ser, concomitantemente, o lugar do visível e do invisível, do possível e do impossível: é um novo estado de vivência, onde seres e acontecimentos fantásticos dividem espaço (de forma mais concreta que se pode pensar) com a guerra. Este estado de vivência foi criado pelo sonho, agora como sinônimo de vontade, das várias vozes contadoras (que são várias, mas expressão de uma vontade social) e do próprio Mia Couto.

\section{Cultura oral / Cultura escrita: a saga de Tuahir e Muidinga}

Ivete Lara Camargos Walty, citando as considerações de Paul Zumthor acerca da escrita literária, afirma que esta, como "texto escrito, fechado no livro, resgata a oralidade não porque promove o retorno da voz e sua supremacia sobre a escrita; antes, ela, através da escrita, promove a circulação dessas vozes em sua pluralidade (...)" ${ }^{1}$ E essa parece ser a "virtude" alcançada pela obra de Mia Couto, particularmente no romance que aqui analisamos.

Os discursos narrativos articulados na referida obra, discursos da tradição oral e da tradição escrita, têm uma função importante quando identificam vários papéis / objetivos, associados às diferentes vozes dessa Moçambique em busca de sua independência/ identidade cultural.

Mas que vozes seriam essas? Quem seriam os ouvintes / leitores que as interpretam? De que modo essas vozes traduzem o cotidiano da Moçambique que se pretende independente? Como se dá esse entrelaçamento entre a História e as estórias retratadas na obra?

Para respondermos a isso analisaremos a composição feita pelo narrador-observador da saga de Tuahir e Muidinga. Este é o tradutor de outras vozes de Moçambique: Tuahir, Siqueleto, Nhamataca, o pastorzito da flauta e tantos outros. Cada uma dessas vozes-estórias é uma peça, mas

\footnotetext{
${ }^{1}$ WALTY, 1997, p. 57.
} 
juntas, no amálgama feito por esse narrador, compõem o mosaico de vivências que é Moçambique.

Depois de uma breve apresentação de um cenário estático, morto, apresentação essa que é feita no pretérito, o narrador marca o início da estória a ser contada incluindo o leitor e introduzindo o presente, tempo que é revelado por meio da flexão do verbo e reforçado pelo uso de advérbios: "A estrada que agora se abre a nossos olhos não se entrecruza com nenhuma outra." [grifos nossos]

Contrariando o modelo de narração em que o início do conteúdo do relato é marcado pelo pretérito - tempo que já instala uma situação em que o narrador tem ciência dos fatos e os retrata com alto grau de certeza sobre as "verdades" que farão parte de sua "fala" -, os capítulos atribuídos a esse "narrador performático" acabam por destruir essa distância temporal entre ele, o leitor e o conteúdo narrado.

Anatol Rosenfeld, ao discutir as transformações por que passou o Romance, explica que, na produção contemporânea, o “... espaço e tempo, formas relativas da nossa consciência, mas sempre manipuladas como se fossem absolutas, são por assim dizer denunciadas como relativas e subjetivas". ${ }^{3}$ Nesses capítulos de Terra sonâmbula, apesar de ser nítida a referência ao tempo da guerra civil que se travou no território moçambicano no período pós-independência política, o leitor experimenta viver junto com os personagens as sensações deles. Assim, o tempo da guerra é revivido por cada leitor a cada vez que ele depara com o texto e a cada leitura é possível ter diferentes e particulares impressões. O tempo da guerra, como tempo histórico, se desfaz e dá lugar ao tempo de existência daqueles personagens, seres ficcionais que sonham a reconstrução de uma nação.

As figuras centrais, focadas pelo narrador, nesses capítulos são Tuahir e Muidinga que, naquele "presente" indefinido, atuam com o único propósito de se manterem vivos e de tentarem vislumbrar alguma esperança para o futuro. Num "jogo do tempo", revelado pelo narrador, vai sendo construída a identidade desses personagens. Tuahir tem um passado; é aquele que pode revelar sua própria identidade e até a identidade de Muidinga. No entanto, ele é o que percebe que não há caminho de volta para a nação em que viveu; nesse sentido, é um desesperançado.

\footnotetext{
${ }^{2}$ COUTO, 1995, p. 9.

${ }^{3}$ ROSENFELD, 1976, p. 79.
} 
O velho the pedira [ao feiticeiro] para que tudo fosse retirado da cabeça dele [ de Muidinga].

- Pedi isso por causa é melhor não ter lembranças deste tempo que passou. Ainda tiveste sorte com a doença. Pudeste esquecer tudo. Enquanto eu não, carrego esse peso... ${ }^{4}$

O passado, para Tuahir, é um fardo, pois torna possível perceber com mais nitidez o estado de ruína em que se encontravam ele, Muidinga e a própria nação. A memória de Tuahir significa, por outro lado, a posse do conhecimento e lhe confere autoridade. É ele quem, numa atitude ritualística de narração, conforme manda a tradição, revela o passado de Muidinga e seu renascimento, revela costumes do seu povo, ensina várias sabedorias ao "miúdo". É importante lembrar que, por mais que a presença de Tuahir se constitua como a daquele contador performático da tradição africana, quem lhe traduz a fala é esse narrador que está próximo, mas "de fora": "O velho, enfim, acede. Limpa o chão onde se vai sentar em preparativo de que se iria demorar. E conta: ele estava no campo de deslocados...". 5

Esse narrador, na verdade, vai organizando o mosaico. Seleciona os fatos, as estórias. Traduz a "fala da tradição". Coloca juntos Tuahir e Muidinga, este personagem que, por sua vez, é apresentado como quem perdeu o passado por causa da doença: doença causada pela fome que o obriga a comer uma planta que não integra sua tradição alimentar, a mandioca brava. Seu estado é como o do povo moçambicano que "adoeceu" se alimentando daquilo que lhe ofertou o estrangeiro e o afastou das tradições. Mas o "miúdo", ao contrário de Tuahir, sabe sonhar, tem esperanças. Enxerga as transformações que são realizadas na estrada e vê as novas paisagens.

O cenário-espaço dessa estória é também impreciso: transforma-se, se renova, assim como as esperanças daqueles que nele vivem.

De fato, a única coisa que acontece é a consecutiva mudança da paisagem. Mas só Muidinga vê essas mudanças. Tuahir diz que são miragens, frutos do desejo de seu companheiro. Quem sabe essas visões eram resultado de tanto se confinarem ao mesmo refúgio. Por isso ele queria uma vez

\footnotetext{
${ }^{4}$ COUTO, 1995, p. 152.

${ }^{5}$ COUTO, 1995, p. 63.
} 
mais partir, tentar descobrir nem sabia o que, uma réstia de esperança, uma saída daquele cerco. ${ }^{6}$

$\mathrm{Na}$ voz desses personagens, quando os deixa falar por meio do discurso direto, ou mesmo em momentos em que aparece o discurso indireto livre, esse narrador deixa aparecer aquilo que é próprio da linguagem da tradição: provérbios, termos africanos, a convocação de costumes: “- Veja essa corda, satanhoco, veja!"’ [grifo nosso]

Mais uma articulação interessante que esse narrador promove é fusão da cultura oral com a cultura escrita. Tuahir e Muidinga descobrem os cadernos de Kindzu, estória contada por escrito. Tuahir pede ao miúdo para que acenda fogo com aqueles papéis. Era um "ignorante das letras", mas não um ignorante. Foi capaz de salvar a vida de Muidinga, apesar de não ter sido capaz de the ensinar a "faculdade da leitura". E apesar de não conhecêla, é influenciado pelas "letras do sonho". Tuahir é quem tem o contato com os representantes da tradição nas figuras de Siqueleto, de Nhamataca e de outros, e é quem possibilita a entrada de Muidinga nesse "ambiente".

Muidinga, na sua falta de passado, não tem consciência de como aprendeu a ler nem de qual seria a importância desse saber, mas ler faz parte daquele que ele é. É Muidinga quem lê os cadernos de Kindzu.

O velho pede então que o miúdo dê voz aos cadernos. Dividissem aquele encanto como sempre repartiram a comida. Ainda bem você saber ler, comenta o velho. Não fossem as leituras eles estariam condenados à solidão. Seus devaneios caminham agora pelas letrinhas daqueles escritos. ${ }^{8}$

É Muidinga quem, por meio da escrita, deixa gravada no embondeiro a tradição de Siqueleto, a qual ali poderá ser perpetuada: tradição e "novidade" se fundem e gerarão frutos.

No tronco Muidinga grava letra por letra o nome do velho. Ele queria aquela árvore para parteira de outros Siqueletos, em fecundação de si. Embevecido, o velho passava os dedos pela casca da árvore. E ele diz: - Agora podem-se ir embora. A aldeia vai continuar, já meu nome está no sangue da árvore.?

\footnotetext{
${ }^{6}$ COUTO, 1995, p. 77.

${ }^{7}$ COUTO, 1995, p. 60.

${ }^{8}$ COUTO, 1995, p. 167.

${ }^{9}$ COUTO, 1995, p. 84.
} 
É no tempo de Muidinga e Tuahir que tradição e oralidade, representadas por este, e modernidade e escrita, representadas por aquele, se juntam em folgações mútuas, em alegres brincriações. À medida que a paisagem muda, esse dois personagens vivem ainda outras estórias que também podem figurar a Moçambique sonambulante: Nhamataca, o fazedor de rio, simboliza a união das margens com o seu repentino rio; o Pastorzito e a estória do tristonho boizarrão - para uma união, uma transformação (quase impossível) necessária.

\section{Sonho/ Racionalidade: um olhar sobre os "Cadernos de Kindzu"}

Os cadernos de Kindzu comportam invencionices verdadeiras, que se fizeram a partir da sua percepção de mundo e de estórias que esse sonhador ouviu das diferentes vozes que povoam Moçambique. O feitiço da escrita aprendera na escola, com o pastor Afonso; com Surendra Valá aprendeu, em tempos de infância, a viajar, a romper as fronteiras geográficas e étnicas. Por causa desses aprendizados, da família Kindzu recebia reprimendas, pois, diferentemente do que manda a tradição, estaria ele a se afastar do seu mundo original. Mundo este cuja representação maior é o pai de Kindzu, o velho Taímo, que, depois de morto, amaldiçoa, em sonhos, seu filho por este querer deixar sua aldeia e assim desrespeitar os costumes.

O jovem, confuso e aterrado pelas ameaças de seu pai, consulta um $n g a n g a,{ }^{\star}$ é figura de grande importância na cultura banto porque possui sabedorias jamais encontradas em outrem; o adivinho o incentiva a empreender as viagens, já que via nos ossinhos mágicos que o jovem não era da terra mas das águas, do mar. Com seus cadernos, Kindzu parte em viagem e vai contando a seus leitores (e os contaminando com isto) o mundo de seus sonhos, em que não há dicotomias, mas sim um amálgama de duas margens, rígidas como a terra, para formação de uma terceira margem, fluida e ondulante como o mar.

De Taímo, Kindzu herdou a doença de sonhar. Para o velho, que seguia sua tradição e apreciava a sura, a bebida da palmeira, os sonhos

\footnotetext{
* Adivinhador. [nota de Mia Couto]
} 
eram o lugar em que se encontravam os ancestrais e deles recebiam-se os desígnios da vida terrestre; a este lugar nem todos tinham acesso, restrito a poucos privilegiados. O visível visitava o invisível. Recebida a herança, o filho não visitaria o invisível: ele uniu em uma terceira margem o natural e o sobrenatural. Além de escutar, Kindzu passa, então, a viver estórias:

De repente, caiu dentro do meu concho um tchóti, um desses anões que descem do céu. (...) Meu pai sempre me contava estórias desta gente que desce os infinitos, de vez em onde. (...) Sempre eu desconfiava das invencionices do velho. Porém, agora, em meu próprio barco passageirava um desses descendentes. ${ }^{10}$

Sonambulante, constitui-se uma nova realidade, em que histórias misturam-se a estórias: "E as estórias se seguiam, se repetiam, trocavam e multiplicavam". ${ }^{11}$ Estas, Kindzu as escuta e depois as reconta, por meio, desta vez, da escrita. Oralidade ${ }^{12}$ e escrita se confundem porque, embora recorrentemente haja uma abertura performática para a contação - "Voute contar minha [Quintino] estória, estrangeiro [Kindzu]."; 13 "Então, me contou [Farida] a sua história"14 -, a voz que narra os fatos, histórias ou estórias, não é a dos próprios contadores mas a do jovem sonhador. Em seus cadernos, ele transcria suas sonhambulânciase as narrações ouvidas, das quais o valor maior não está numa hipotética única verdade; está, isso sim, na possibilidade de através das vozes individualizadas formar um coro coletivo: Farida une em si crenças/costumes locais e valores portugueses ao ir para a Missão - onde aprendera a rezar -, ao conviver com Virgínia sua segunda mãe que, por sua vez, era "branca de nacionalidade, não de raça" e tinha o português como "sua língua materna e o makwa, ${ }^{\star}$ sua maternal linguagem"15 - e ao ter um filho de Romão Pinto, representação máxima do colonizador, mas que nem por isso deixa de misturar-se, no sentido de troca, com Moçambique:

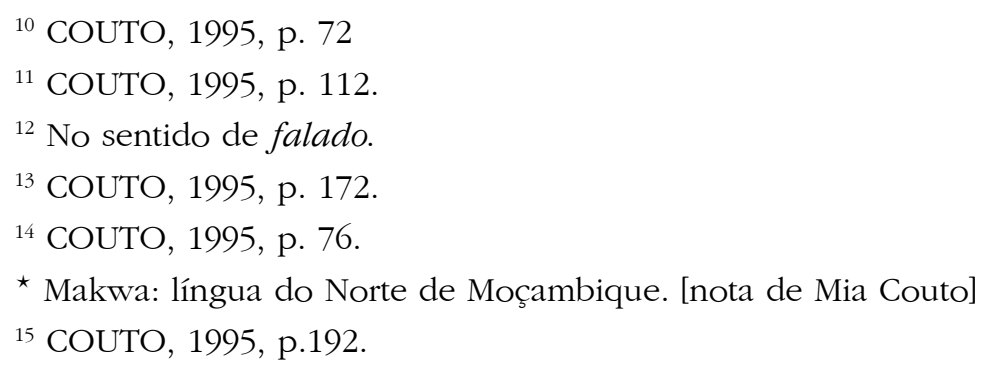


Ele [Romão] nem queria escutar [as explicações de Salima, esposa de um maometano]. Vinha à mente era a voz da crença, condenando aquele que ama uma mulher em estado de impurezas. Também o português punha crédito em tais africanas maldições: nele os sangues haveriam de escorrer, transbordantes. ${ }^{16}$

A voz de Kindzu está inscrita (e por baixo dela estão inscritas as diversas vozes que formam uma Moçambique não de extremos mas de meio) e disponível para quem pudesse propagá-la no ar. Foi isso que fez Muidinga, ao ler para si e para Tuahir os cadernos, e assim, também, ambos passarem a viver sonhambulâncias. "Tire só essa papelada. Serve para acendermos a fogueira." ${ }^{17}$ metaforicamente uma fogueira se acendeu com a leitura dos escritos porque levou vida e movimento a uma estrada morta, impedida de sonhos; emprestou uma memória ao miúdo, aliás Kindzu, ${ }^{18}$ e deu ao velho, aliás Taímo, o sabor de voltar a ser pai.

Mia Couto realizou o seu sonho. Conseguiu traduzir a riqueza da cultura mestiça de Moçambique; a síntese da complexa diversidade que configura aquela nação. Conseguiu fazer de sua obra uma linguagem que atingiu um transe, como a dança dos moçambicanos

naquele exato momento em que eles [os dançarinos] estão entrando em transe para serem possuídos pelos espíritos. Aquele flagrante daquele momento em que aquilo já não é dança, mas já é outra coisa. ${ }^{19}$

\footnotetext{
${ }^{16}$ COUTO, 1995, p.180.

${ }_{17}^{17}$ COUTO, 1995, p.13.

${ }^{18}$ COUTO, 1995, p.187.

${ }^{19}$ COUTO, 1998, p. 12.
} 


\section{Referências Bibliográficas}

ALTUNA, P. Raul Ruiz de Asúa. Cultura tradicional banto. p. 270-272; 583-587.

COUTO, Mia. Nas pegadas de Rosa. Scripta, Belo Horizonte, v.2, n.3, p. 1113, $2^{\circ}$ sem. 1998.

COUTO, Mia. Terra sonâmbula. Rio de Janeiro: Nova Fronteira, 1995.

HARRISTS, Kirsten Folke; SHARNPERG, Ditte. Encontro com o contador de histórias: um processo de aprendizado mútuo. História oral, Revista da Associação Brasileira de História Oral, São Paulo n. 3, junho de 2000.

HELD, Jacqueline. O imaginário no poder. as crianças e a literatura fantástica. 2. ed. São Paulo: Summus, 1980.

NEVES, Lucilia de Almeida. Memória, História, sujeito: substrato da identidade. História oral, Revista da Associação Brasileira de História Oral, São Paulo n. 3, junho de 2000.

ROSA, J.G.Primeiras estórias. 45ํㅡㄹ. Rio de Janeiro: Nova Fronteira, s./d.

ROSENFELD, Anatol. Texto/Contexto. São Paulo: Perspectiva, 1976, p.75-97: Reflexões sobre o romance moderno.

SCHIPPER, Mineke. Literatura oral e oralidade escrita.(Texto traduzido por Fernanda Angélica Mourão (Oficina de texto - FALE/UFMG), a partir do original inglês "Oral Literature and Written Orality", extraído de: SCHIPPER, Mineke. Beyond the Boundaries: African Literature and Literary Theory. London: Allison \& Busby, 1989.)

TODOROV, Tzvetan. As estruturas da narrativa. 2. ed. São Paulo: Perspectiva, 1970. p.147-166: A narrativa fantástica.

WALTY, Ivete Lara Camargos. Circunavegações literárias entre o oral e o escrito. Scripta, Belo Horizonte, v. 1, n.1, p.53-61, 2으 sem. 1997.

http://www.macua.com/Mia_Couto_Amecom2003.htm 


\section{Resumo}

Como nação que lentamente se liberta do jugo da colonização, mas que já foi (e ainda é) marcada pela cultura do outro, Moçambique tem, na literatura, autores que conseguiram evidenciar a tensão existente entre a tradição e a "cultura nova" que se infiltrou no território africano principalmente a partir do processo de colonização. É de forma sensível e desvestida de preconceitos que um desses autores, Mia Couto, em seu romance Terra sonâmbula, aponta a existência dessa teia de influências que atua na construção da identidade do povo moçambicano. Oral/ escrita; sonho/ lógica e racionalidade: dois pares de aspectos que, se em princípio parecem se constituir como dicotômicos, acabam por revelar, na obra, a defesa de uma mestiçagem como condição harmonizadora da tensão entre tradição e "cultura nova". O caráter mestiço da nova Moçambique seria um terceiro "estado de alma" do povo; na obra, um estado sonhambulante: estado de quem sonha, mas age como se estivesse acordado. Assim o visível e o invisível, o possível e o impossível formam um novo estado de vivência, onde seres e acontecimentos fantásticos dividem espaço (de forma mais concreta que se pode pensar) com a guerra.

\section{Abstract}

As a nation that slowly frees itself from the colonization, but has been (and it still is) stamped by other cultures, Mozambique has, in its literature, autors that were able to show the tension between tradition and the new culture, that had entered in Africa manly by the colonization process. It's in a sensitive way, with no prejudice that one of these authors, Mia Couto, in his romance Terra sonâmbula, shows the existence of this influence net that performs the identity building process of the people from Mozambique. Oral/ written, dream/ logic and sense: two pairs of aspects that, if in the beginning seem to be opposites, in this work, they reveal themselves the defense of the halfcasteness as a balancing condition of the tension between tradition and new culture. The halfcaste side of the new Mozambique would be a third "soul state" of the people; in the work, a "sonhambulante" state (this word is formed by three words: dream sleep-walker and walking): the state of one who dreams, but acts as if were awake. Thus, the visible and the invisible, possible and impossible form a new living state, where beings and fantastic events share the spaces (in a more concrete way that one may think) with the war. 